\title{
Tackling difficult situations: supporting your staff and students
}

Anonymous

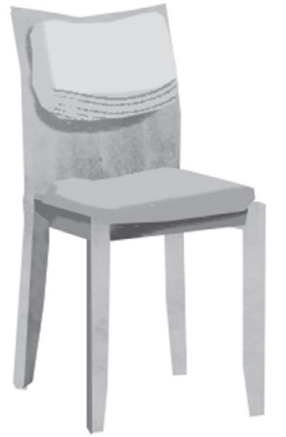

In my first month as a staff member at the University and brand-new lab head, I hired my first postdoc. She is an amazing scientist, but I soon realized that she had a problem with the working environment. She had been working in the same department during her PhD, and warned me when I started that a member of staff in the building was "creepy". As a line manager, I was not sure what I should do (if anything) about someone being "creepy" and asked her if there was anything I could do to help the situation. She said no, that it was fine. This was a big mistake - I should have tried harder to find out what was going on.

It was only several months later that she was brave enough to tell me what exactly "creepy" meant. In this case, it meant a member of staff making incredibly inappropriate, explicit jokes and references to several young women's anatomy and sex lives. I was absolutely shocked when I heard details of what had been said. With more prompting, I found out that she had mentioned it to her (older, male) PhD supervisor in the department. I think it took a lot of courage for her to bring it up, and her supervisor's reply: "Well, that's just him; we can't piss him off, he's really good at his job". This is wrong on so many levels! I slept on it and the next day went straight to HR (Human Resources).

When I started to tell the story, it turned out that multiple people had previously complained and HR was aware of the situation, but as a complaint had been withdrawn they could take it no further. I found it frustrating that HR had been unable to do anything, but there were confidentiality issues which meant they couldn't fully discuss the history with me. I offered to speak to the "creepy" person and make it clear that this harassment was completely unacceptable and making people uncomfortable. HR advised that his line manager would handle it. I was absolutely livid with the entire situation, but to their credit, HR and the line manager did handle it and all is much smoother now in the department (at least to my knowledge). And I avoided the confrontation with the offending member of staff that I was very anxious about. I also learned a lot about managing people, and now every time I have a new student or member of staff, and at everyone's annual review or before their thesis committee meeting, I let each person know that if they are uncomfortable at work for any reason, I would really like to hear about it and can help take care of the situation.

\section{Ingredients}

- Resolve to tackle uncomfortable situations.

- $\quad$ Phone number for HR representative.

- $\quad$ Note to self to remind all students and staff to tell someone if they are uncomfortable. 


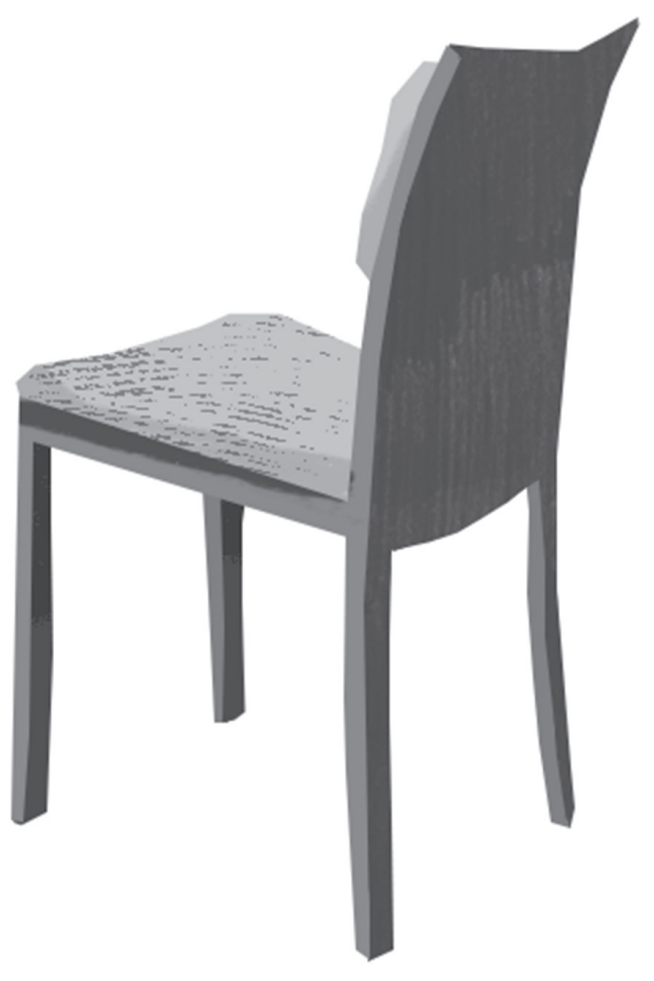

\section{Method}

1. Inform students and staff that they should never be made to feel uncomfortable at work. They should be briefed about this both when they arrive and at annual reviews or before thesis committee meetings.

2. Listen out for people who are uncomfortable at work - they may use subtle hints!

3. Work up the courage to tackle an uncomfortable situation with colleagues.

4. Work with HR or with the people involved, making it clear that any kind of harassment is not acceptable, even if they think it is a joke.
The University of Edinburgh has recently launched the No One Asks For It campaign (http://no-oneasksforit. com/support) which makes it very clear that sexual harassment is unacceptable:

"We're challenging sexual harassment and violence on our campuses. We want our University to be a place where students and staff feel respected, supported, and safe.

The term 'sexual harassment' is used to describe any unwelcome behaviour of a sexual nature, from what is often thought of as 'harmless banter' through to sexualised jokes, wolf-whistling, and unwanted physical contact including groping and even sexual assault. Sometimes sexual behaviour can be consensual but if someone else is making you feel uncomfortable, intimidated, or humiliated then it is harassment.

Edinburgh University Students' Association, Edinburgh University Sports Union and the University of Edinburgh are clear that sexual harassment, in any form, is never acceptable." 